LSP International Journal, Vol. 5, Issue 2, 2018, 17-35

(C) Universiti Teknologi Malaysia

E-ISSN 2601-002X

DOI: https://doi.org/10.11113/lspi.v5n2.72

\title{
A Corpus-Based Study of Reformulation Markers across Different Disciplines
}

\author{
Mohammad Alipour \& Anis Saadatidust \\ Department of English Language Teaching, Ahvaz Branch, Islamic Azad University, Ahvaz, Iran
}

Submitted: 16/08/2018. Revised edition: 18/10/2018. Accepted: 22/10/2018. Published online: 20/12/2018

\begin{abstract}
This study presents a corpus-based study of reformulation markers as a common metadiscourse device in research articles of three different disciplines, namely, applied linguistics, computer engineering, and physics. Toward this end, qualitative and quantitative analyses of reformulation devices were conducted. Three sub-corpora were compiled by downloading articles from academic journals of each discipline selected via convenience sampling. Each corpus included approximately one million words. All the analyses were conducted through employing Murillo's (2004, 2007) classification which consists of three broad categories: explicit meaning functions (identification, specification, and explanation), conceptual meaning functions (definition and denomination), and implicit meaning functions (conclusion and mathematical operation). Chi-square tests were performed to determine whether the results found in the analysis were statistically significant. The results revealed that there were differences between the functions of reformulation markers (RMs) across different disciplines. In particular, the three disciplines differ in terms of their types, and functions, and writers of physics research articles (RAs) use RMs much more frequently than writers of applied linguistics and computer engineering RAs. In light of the findings, recommendations are made for EAP classes.
\end{abstract}

Keywords: Corpus, Discipline, Metadiscourse, Reformulation Markers, Frequency, Function

\subsection{INTRODUCTION}

The word metadiscourse was coined by Harris in 1959 to refer to text segments "that hold data of only secondary importance" (Beauvais, 1989, p. 11). Vande Kopple (1985) characterizes metadiscourse as "discourse about discourse or communication about communication" (p. 83). By this, he implies that metadiscourse helps readers in their endeavors to organize, classify, interpret, evaluate, and respond to the propositional substance of the content. Essentially, Crismore and Farnsworth (1990) describe metadiscourse as the "writer's overt and non-overt presence in the discourse in order to direct rather than to inform readers "(p. 119). Based on a perspective of writing as a social and open engagement, metadiscourse centers our consideration on the way writers project

*Correspondence to: Mohammad Alipour (email: alipour83@yahoo.com) 
themselves into their work to indicate their informative plans (Hyland, 1998). The term metadiscourse can serve what Halliday (1978) calls the text-based and interpersonal capacities of language. It can, thus, be considered as a significant characteristic of a text which helps its textuality by serving as the glue which bonds the propositions together and develops both cohesion and coherence (Jalilifar \& Author, 2007)

Given the significance of metadiscourse in academic disciplines, from among eleven academic discipline classifications provided by Braxton and Hargens (1975), five have the most empirical attention: the Hagstrom Model (1964) on the basis of the idea of disciplinary agreements, the Lodahl and Gordon Model (1972) based on levels of paradigm development, and the Biglan Model (1973) based on the hard/soft, pure/applied, and life/non-life distinction, the Hargens Model (1975) based on normative and functional integration, the Zuckerman and Merton Model (1986) based on disciplinary codification, (Braxton \& Hargens, 1996). Each of these classification schemes is rooted in the idea that every field of study has different levels of paradigmatic development according to their level of agreement. Fields with high paradigmatic development enjoy high levels of agreement with regard to issues such as appropriate research topics and methods (Braxton \& Hargens, 1996). Fields with low paradigmatic development, however, have less agreement with regard to the appropriate research questions for their field and even less agreement on the appropriate methodology for addressing these questions (Alise, 2007; Kuhn, 1970).

Considering the salience of academic language, linguists and discourse analysts have paid increasing attention to academic disciplines. Rhetorical structure (Swales, 1993, 2004) and metadiscursive features (Author \& Matouri, 2017; Hyland, 2005; Hyland \& Tse, 2004; Jalilifar \& Author, 2007; Jalififar \& Shooshtari, 2011; Kahkesh \& Author, 2017) have been studied in order to examine disciplinary and generic differences (Hyland 1999, 2000, 2004, 2005) in academic texts written in English, mainly in research articles, book reviews, and textbooks. To work in a discipline, linguists need to be able to engage in these practices and, in particular in its discourses. Hence, disciplines structure the work within wider frameworks of beliefs and provide the conventions and expectations that make texts meaningful. For example, it is believed that applied linguistics as a discipline in humanities, is explicitly interpretive, has a more varied readership and a more fluid discourse, and guides the readers to make their own meaning (Creswell, 2009). Physics and computer engineering research articles, as quantitative research articles, have their own ways to provide conventions and put forth their claims, and they aim to create explicit, coherent, systematically principled organization of knowledge (Bernstein, 1996, 1999).

Essentially, we can see disciplines as language using communities and the term helps us join writers, texts, and readers together. Communities provide the context within which we learn to communicate and to interpret each other's talk; therefore, we can see different disciplines as particular ways of doing things, particularly of using language to engage with others in certain familiar ways. Wells (1992) believes that:

Each subject discipline constitutes [different] ways of making sense of human experience that has evolved over generations and each is dependent on its own particular practices: its instrumental procedures, its criteria for judging relevance and validity, and its conventions of acceptable forms of argument. In a word each has developed its own modes of discourse (p. 290). 
Nonetheless, this deterministic view has been challenged by Carter (2003). He believes that a text does not exist in a vacuum but naturally refers to other texts that are essential for its understanding, thus, to increase language awareness within the parameters of form and function, learners should be encouraged to view language as a system and to examine what language does in the given context. This was a shift from a schemata-view to a language-awareness-view defined as "the of an enhanced consciousness of and sensitivity to the forms and functions of language" (Carter, 2003, p.64).

As a subcategory of metadiscourse markers, one of the most important examples of institutional discourse features is the speakers' use of reformulation markers which are a significant discourse phenomenon in academic discourse (Thoiron \& Bejoint, 1991). These markers serve as a discourse function which enables speakers to explicate an idea and be more lucid and "facilitate the hearer's understanding of the original or to develop the previous information" (Blakemore, 1993, p. 125). Reformulation is described as an act when one single proposition is put forth via two expressions in which the second is an interpretation of the first. Some academics regard it as an equivalence act at the metatextual level (Bach, 1996; Cabre, 1995; Fuentes, 1993).

It is perhaps the most salient element when some utterance is produced by somebody which has been paraphrased beforehand or mentioned in a different way (e.g. in other words) and believes that they could be related either from semantically or pragmatically. However, it should to be looked upon as a complex semantic classification which runs a wide gamut from paraphrase to other values including specification, explanation, summary, or denomination, and even to non-paraphrastic meanings such as implication, conclusion, and contrast (Cuenca, 2003).

One can also view reformulation as a discourse phenomenon in academic discourse (Thoiron \& Bejoint, 1991). These techniques are entwined with communication: authors commonly make recourse to them to return to what they have composed previously, bearing in mind the final purpuse to expand, specify, clarify, or define it. They may make use of such markers for that reason (Gulich \& Kotschi, 1983). In English, some of these markers can include that is, that is to say, in other words, i.e., and namely, together with different less grammaticalized markers such as to put it another way, to put it simply, to put it differently, in plain words, etc.

Reformulation markers are a sort of discourse markers which function to upgrade integration in discourse (Schourup, 1999). Murillo (2004) calls them "markers of the explicit" as these discourse markers "aid, to shifting degrees, in the inferential process by making explicit reference assignment, disambiguation, further improvement and elliptic material regarding the recuperation of the propositional structure" (p. 2066). Murillo (2004) sees, from the perspective of Relevance Theory that reformulation markers not only function to recover the propositional form of an expression, but they also operate in connection to its explicatures and implicatures "by explicating implicated premises and conclusions" (p. 2066).

The glossing and explicating functions of reformulation markers render them especially relevant to the explicitation theory in translation universal research. For example, Baker (2004) finds that reformulation markers, for example, that is, that is to say, and in other words, are more frequent in fiction and biography components of the Translational English Corpus than in the fiction sub-corpus of the British National Corpus. Mutesayire (2005) views the higher frequency of reformulation markers in translated English as confirmation of explicitation.

Blakemore (1993) examined all instances of reformulation in a range of both literary and nonliterary samples and demonstrated that reformulation serves a variety of aims, such as making 
relevance. In a technical content, a reformulation may oblige the understanding of the original with the end goal of guaranteeing a more correct understanding of a specific idea, and thus a greater understanding of the surrounding text. In another study, Cuenca (2003) dissected the reformulation markers in English, Spanish, and Catalan. The study was focused around a corpus of expository composition, mainly academic writing. The examination demonstrated the frequency of the markers and differences in the variety of forms expressing reformulation and also in their recurrence of utilization. It was shown that those markers prompting the making of connectives have their roots in discourse, parallel differences are required to be found in content development. He contended that the divergences identified in the linguistic use of English versus those of Spanish and Catalan could be connected with two different styles for building academic texts.

Bach and Cuenca (2007) investigated the structure and utilization of reformulation markers in examination papers composed in English, Spanish, and Catalan. Considering the form and frequency of the markers, English papers had a tendency to incline toward basic altered markers and included less reformulators than Spanish and Catalan. Unexpectedly, formal Catalan and Spanish papers included more markers, some of which were intricate and considered some structural variability. Concerning utilization, reformulation markers secured element connections between shares of discourse which could be recognized in our corpus with expansion, reduction and permutation The examination of the corpus demonstrated that English authors normally reformulated to add more data to the idea (expansion), while Catalan and Spanish authors reduced the substance or the implicatures of the previous formulation more frequently than English.

Xiao (2011) conducted a contrastive investigation of word clusters and reformulation markers in Chinese and English and discussed the implications of discoveries for interpretation of Universal theories. The study was focused around three adjusted practically identical corpora which Represented British English, native Chinese and translational Chinese. There was also an EnglishChinese parallel corpus which gave a premise to contrasting native and translated English and researching explicitation in translation. The results illustrated that word clusters were more regular in translated Chinese. Chinese and English tended to use reformulation markers of diverse styles, while reformulation markers were by and large more basic in both translated English and translated Chinese than in their native counterparts.

Murillo (2012) explored the utilization of reformulation markers as a typical metadiscourse device in L1 English and Spanish and in L2 English research articles of a specific discipline, namely, Business Management. These markers are viewed as procedural items, i.e. they encode data on how to process lexical meaning (Murillo, 2012). The general recurrence of utilization of the markers, the types of markers utilized, the functions most commonly performed, and their (non-)parenthetical utilization were compared in order to detect the degree of transference in their use by the LI Spanish academics writing L2 English articles. The results were contrasted with comparable studies on reformulation markers in general English and Spanish in addition to studies in other disciplines. The results uncovered that some general rhetorical L1 features are more likely to be adjusted in the L2 texts written by L1 Spanish academics than other more specific grammatical features.

Given the fact that the majority of research has been carried out on reformulation markers, there is a clear dearth of disciplinary studies of RMs. While cross-cultural RMs research has been conducted in a few languages, with the comparative language often being English, Spanish, and 
Catalan (e.g. Author \& Nooreddinmoosa, 2018; Bach \& Cuenca, 2007; Cuenca, 2003; Murillo, 2012), it appears that to date no disciplinary study has been conducted that examines the use of RMs and their functions in different academic disciplines. The current study, thus, aims to conduct a crossdisciplinary analysis of the frequency, types, and functions of RMs to find out the differences which might exist in research articles of three disciplines, namely, computer engineering, physics, and applied linguistics. In order to conduct a comprehensive analysis, this study attempts to explore the following research questions:

Q1. Do the frequency and types of reformulation markers differ significantly in the English RAs of physics, computer engineering, and applied linguistics?

Q2. Do the functions of reformulation markers differ significantly in the English RAs of physics, computer engineering, and applied linguistics?

\subsection{METHODOLOGY}

\subsection{Corpora}

The data for this study comprised of a total of more than three million words from three disciplines: applied linguistics, computer engineering, and physics, each comprising approximately one million words. The compilation of all corpora included the main text, general title, titles of sections and subsections, and footnotes/endnotes. The reason behind selecting these disciplines was to include different camps of science, that is, applied linguistics as a representative of humanities, computer engineering as an applied science, and physics as a pure science. Moreover, the reason behind this selection stems from the possible disciplinary differences in the type of language employed by research article authors from different disciplines (Hyland, 2008). The RAs were selected from well-established journals of each discipline. Their selection was informed by their inclusion in the Web of Science Website (http://thomsonreuters.com/) and was based on convenience sampling and the accessibility of their articles to the researchers. That is why there were five journals for applied linguistics, five journals for computer engineering, while there were four journals for physics. The period of their publication ranged from 2005 to 2017 which was a 12 -year period to enable the researchers to download a sufficient number of articles and compile a corpus of a minimum of one million words for each discipline.

The applied linguistics, physics, and computing articles were selected from these journals: Applied Linguistics (AP), System, Journal of Pragmatics (JP), English for Specific Purposes (ESP), and Discourse and Society (DS), Applied Physics B Journal (APBJ), Atomic Energy Journal (AEJ), Journal of Applied Physics (JAP), Acoustical Physics Journal (APJ), Journal of Computer-Mediated Communication (JCMC), Journal of Computer Science and Technology (JCST), General European Journal of Computer Science ( GEJCS), Engineering and Computer Iournal (ECJ), and Mathematics Education Research Journal (MERJ). The following table shows the number of articles included in the corpus from each discipline. 
Table 1 Number of Articles in Each Discipline

\begin{tabular}{ll}
\hline Disciplines & Number of Articles \\
\hline Applied Linguistics & 180 \\
Computer Engineering & 274 \\
Physics & 390 \\
\hline
\end{tabular}

As can be seen, the numbers are different on the ground that the length of articles was different for each discipline to make a corpus of nearly one million words. For example, while applied linguistics articles comprise approximately 6000 words on average, the average length for physics articles is roughly 3000 words.

\subsection{Instrumentation}

Two instruments were employed in the present study. The first one was AntConc freeware available at https://laurenceanthony.net, and the second one was the classification of functions of reformulation markers proposed by Murillo (2004, 2007). AntConc is a freeware, multiplatform tool for carrying out corpus linguistics research and data-driven learning. It contains seven tools: Concordance, Concordance Plot, File View, Clusters, Collocates, Word List, and Keyword List. We used the Word List tool for counting the total number of words in all the articles and used Concordance tool for counting the number of RMs in all the articles.

The analysis was carried out according to the classification proposed in Murillo (2004, 2007) which integrates the typologies proposed by Fluttum (1994), Gulich and Kotschi (1995), and Quirk, Greenbaum, Leech and Svartvik (1985). This classification takes as a basis the process of utterance interpretation as explained by Relevance Theory (Blakemore 1987; Wilson \& Sperber 2004) and considers reformulation discourse markers as procedural items that contribute to the different stages in this process, by guiding the inferences that the hearers/readers make when they interpret utterances.

Given the nature of reformulation markers, the typology of functions in this framework is closely associated with the contextual and co-textual presentation of information and content, and consists of three broad categories or macro-functions: first, functions related to the interpretation of explicit content, including coreference/identification and specification, i.e. where the markers assist in reference assignment, introducing the referents, and explanation where the whole explicit import of an utterance is restated or clarified; second, functions related to conceptual or encyclopedic knowledge, with definition and denomination markers, to generate the necessary background for interpretation; and third, functions in which the markers introduce implicated conclusions, thus helping in the recovery of implicit content: conclusion and quantification/mathematical operation. The following table summarizes the functions of RMs. 
Table 2 Functions of RMs

\begin{tabular}{ll}
\hline Function & \\
\hline Explicit meaning functions & Identification \\
& Specification \\
& Explanation \\
Conceptual Knowledge Function & Definition \\
& Denomination \\
Implicit Meaning Function & Math. \\
& Conclusion \\
\hline
\end{tabular}

On the basis of the above framework, the functions of reformulation markers were analyzed and classified by two raters separately in a pilot study. Toward this aim, the two researchers, who were the raters, first studied and discussed the framework closely and attempted to reach agreement over the best definition for each category of functions and tried to find examples for them. After this step, each of the raters separately analyzed 20 percent of the corpus based on the agreed-upon framework. Finally, to ensure the inter-rater reliability of the analysis, Phi correlation was run. The obtained coefficient was 0.87 which manifested that the method adopted to analyze the functions of RMs across the research articles of each discipline was reliable.

\subsection{Procedure}

Before conducting the main analysis of the corpora, a pilot study was carried out in which two raters crosschecked the reliability of RMs classification which was employed. After reading all the RAs carefully, the articles were searched for RMs, the words which function as these devices were marked and put in their proper categories regarding their function in the context they were embedded. It is worth mentioning that, apart from the reformulation markers scrutinized in the present study, there were some others such as to put it differently, to say the same thing differently, in plain words, to put it simply, and to put it bluntly which were excluded from the analysis simply on the ground that they occurred very infrequently in the data so much so that they could not lend themselves to the analysis. In our corpora, only one of them, to put it simply, occurred twice so that they were excluded from the analysis. The type of each marker was detected and then the frequencies of all of them were counted in all the RAs.

\subsection{RESULTS}

In this section, the frequencies and percentages of the types of all the RMs in the corpora are presented and compared through Chi-square. Tables 3 manifest the types of RMs across the disciplines. 
Table 3 Types of RMs

\begin{tabular}{llll}
\hline Types & \multicolumn{3}{l}{ Disciplines } \\
\cline { 2 - 4 } & Applied Linguistics & Computer Engineering & Physics \\
\hline That is & $160(29.73 \%)$ & $124(28.31 \%)$ & $38(5.75 \%)$ \\
That is to say & $20(3.71 \%)$ & $0(0 \%)$ & $50(7.57 \%)$ \\
Namely & $82(15.24 \%)$ & $40(9.13 \%)$ & $44(6.66 \%)$ \\
In other words & $58(10.78 \%)$ & $74(16.89)$ & $26(3.93 \%)$ \\
i.e. & $218(40.52 \%)$ & $200(45.66 \%)$ & $502(76.06 \%)$ \\
Total & $538(100 \%)$ & $438(100 \%)$ & $660(100 \%)$ \\
Chi-square & & 0.0 & \\
\hline
\end{tabular}

As the table above manifests, in applied linguistics RAs, i.e. with $40.52 \%$ and that is to say with $3.71 \%$ were the most and the least frequent RMs respectively. Concerning computer engineering RAs, the most recurrent RMs was i.e. $(45.66 \%)$; on the other hand, that is to say was not used at all. With regard to physics RAs, similar to the other two disciplines i.e. (76.06\%) was the most repeated marker and in other words $(3.93 \%)$ was the least frequent one.

According to the above table, Chi-square value (0.0), which is substantially below 0.05 , indicates significant differences in the frequency rates of RMs in each discipline. It means that the writers of different academic disciplines apply reformulation markers in their research articles in different ways.

More specifically, the findings reveal that the use of RMs was the highest in the physics corpus ( $N=660)$, while it was the lowest in the computing engineering corpus ( $N=438$ ). The most remarkable differences include the percentage and frequency of $i . e$. marker in these disciplines which was the most frequent marker in them all, occurring 502 times in physies, 218 times in applied linguistics, and 200 times in computing engineering RAs. In these disciplines, the lowest frequency belonged to that is to say which appeared 50 times in physics, 20 times in applied linguistics and none in computing engineering. Some examples of RMs in the three disciplines are given below:

\section{Applied Linguistics}

1. "Direct speech initiator by means of this marker the speaker introduces quoted material, i.e. direct speech." (Discourse and Society, 2005, Introduction)

2. "Combine with second level instructions (Luscher, 1994), namely, denomination, designation, exemplification, correction, conclusion, argumentation, level change and degree of specialization. Finally, these specific meanings or moves." (Journal of Pragmatics, 2007, Methodology)

3. "Similarly, the use of $I$ mean in evaluation segments, internal evaluation mainly, also responds to its core function, that is, showing the hearer involvement of the self and the other." (Applied Linguistics, 2007, Results) 


\section{Computer Engineering}

4. "Furthermore, individuals using computer-mediated negotiation did not have to worry as much about visual cue leakage. That is, because the deceivers were not face-to face, they did not have to worry about hiding the physical cues to deception." (Journal of ComputerMediated Communication, 2007, Discussion)

5. "Communication overhead can be broadly categorized as either per-message overhead (incurred on each message regardless of its length) or per-byte overhead (i.e., proportional to the size of the message being transmitted)." (Journal of Computer Science and Technology, 2011, Introduction)

6. "Session Relationship Constraints stipulate the relationship between the two consecutive sessions. In other words, the relationship between the existing lightpaths and the new lightpath demands." (Journal of Computer Science and Technology, 2010, Introduction)

Physics

7. "As a result, the boundary of a domain with the diameter $\mathrm{D}>\mathrm{H}$ will apparently move one dimensionally on the time scale of the radial domain expansion. In other words, a larger dynamic characteristic length along the polar axis should be introduced for moving ferroelectric domain walls instead of the static Larkin length." (Journal of Applied Physics, 2011, Abstract)

8. "One difficulty in experiments using surface electrode traps is that the trap depth is more than one order of mag- nitude smaller than that of a conventional linear Paul trap of the same size (i.e., with the same distance between the trapped ion and the nearest electrode)." (Journal of Applied Physics, 2011, Conclusion)

9. "In contrast to the active researches on gas phase molecules, the interaction of intense laser fields with solid molecules, that is the laser ablation, has been limited mainly to the material processing and researches on the fundamental processes are required." (Acoustical Physics Journal, 2008, Introduction)

Regarding the functions of the RMs, the frequencies and percentages of all the RMs in the three corpora are presented and compared through Chi-square in the following table. 
Table 4 Functions of RMs

\begin{tabular}{|c|c|c|c|}
\hline \multirow[t]{2}{*}{ Functions } & \multicolumn{3}{|l|}{ Disciplines } \\
\hline & Applied Linguistics & Computer Engineering & Physics \\
\hline Identification & $32(5.94 \%)$ & $16(3.65 \%)$ & $54(8.18 \%)$ \\
\hline Specification & $190(35.31 \%)$ & $148(33.78 \%)$ & $184(27.87 \%)$ \\
\hline Explanation & $260(48.32 \%)$ & $238(54.33 \%)$ & $308(46.66 \%)$ \\
\hline Definition & $36(6.69 \%)$ & $12(2.73 \%)$ & $52(7.87 \%)$ \\
\hline Denomination & $4(0.74 \%)$ & $14(3.19 \%)$ & $30(4.54 \%)$ \\
\hline Conclusion & $16(2.97 \%)$ & $4(0.91 \%)$ & $2(0.30 \%)$ \\
\hline Math & $0(0 \%)$ & $6(1.3 \%)$ & $30(4.54 \%)$ \\
\hline Total & $538(100 \%)$ & $438(100 \%)$ & $660(100 \%)$ \\
\hline Chi-square & & 0.0 & \\
\hline
\end{tabular}

As you can see in Table 4, results showed the most frequent function was explanation (48.32\%), whereas the least frequent one was denomination (4\%). The overall results of analyzing broad category of RMs, which included explicit meaning functions, conceptual knowledge functions, and implicit meaning functions, are as follows: explicit meaning functions were the most frequently used type of RMs (89.57\%), followed by conceptual meaning functions $(7.43 \%)$ and implicit meaning functions $(2.97 \%)$.

Concerning computer engineering RAs, the most frequent function was explanation accounting for $54.33 \%$ of functions, and the least frequent function was conclusion making up $0.19 \%$ of functions. Analysis of the broad categories of functions indicated that explicit meaning functions, conceptual meaning functions, and implicit meaning function were utilized $91.76 \%, 5.92 \%$ and $2.21 \%$ respectively. Among these functions, explicit meaning functions were the most repeated ones. Some of these functions are exemplified below referring to the part of the article they were detected:

\section{Identification Function}

10. "For a systematic indication of developments at the specialty level, one obviously has to zoom in on a one-lower level of analysis, that is, the specific citation pattern of individual journals." (General European Journal of Computer Science, 2010, Result)

\section{Specification Function}

11. "Initially, we organized cybercrimes into five basic categories, namely, intrusion, malicious code, denial of service attacks, digital piracy, and all others." (General European Journal of Computer Science, 2008, Introduction) 


\section{Explanation Function}

12. "This fact, combined with the deficiency of the criminal justice system, highlighted the need to better understand the attacker's state of mind, i.e., his or her psychology, given that the ultimate goal is to dissuade potential cybercrimals from launching attacks." (Mathematics Education Research Journal, 2007, Discussion)

With regard to physics, among all the functions in physics RAs, explanation $(46.66 \%)$ and conclusion $(0.3 \%)$ were the most frequent and the least frequent ones. The results of analyzing broad categories reveal that explicit meaning functions were the most frequent functions as $82.71 \%$ of RMs, followed by conceptual meaning functions $(12.41 \%)$ and implicit meaning functions (4.84\%). The followings are some of these functions in the physics corpus:

\section{Identification Function}

13. "The silicon oxide thickness that determines the device conductivity in the tunneling processes. Although both devices have the same nominal thickness of the oxide, the actual values obtained from ellipsometry studies are different, namely: $1.5 \mathrm{~nm}$ for $\mathrm{W} 10$ and $1.8 \mathrm{~nm}$ for W9." (Applied Physics B Journal,2014, Result)

\section{Specification Function}

14. "The electrode voltage mostly affects the potential in the rf amplitude was modulated by mixing with another rf signal with a frequency scanned near twice the secular frequency (i.e., 2 my)." (Acoustical Physics Journal, 2014, Result)

\section{Explanation Function}

15. "However, when comparing a nonbroadened asymmetric waveguide with a broadened symmetric one with the same effective mode distribution width heff (that is, with the same equivalent spot size), the asymmetric structure offers a considerable advantage." (Applied Physics B Journal, 2012, Discussion)

16.

Some examples are provided for the applied linguistics texts below:

\section{Identification Function}

17. "Characterizing a complaint as expectable from the complainant, i.e. as dispositional, can be a way of undermining its factual basis or seriousness." (English for Specific Purposes, 2008, Abstract) 


\section{Specification Function}

18. "From the perspective of CDA, Wodak $(1996,2000)$ analyses the disorders in discourse that arise when institution insiders namely the social elite come into contact with outsiders in other words normal citizens." (Discourse and Society, 2007, Introduction)

\section{Explanation Function}

19. "Ultimately, then, whilst there may be something which resembles hierarchy within the Townie CofP (with Ellie positioned as both sociolinguistic icon and dominant speaker) what Ellie represents is collaboratively constructed. That is to say, Ellie's representation of Townieness draws upon what is collectively represented as Townie-ness in group interactions like the narrative observed here." (System, 2006, Discussion)

According to the above table, Chi-square value (0.0), which is significantly below 0.05 , is indicative of significant differences in the frequency of $\mathrm{RMs}$ ' functions in each discipline. It means that the writers of different academic disciplines applied reformulation markers in their research articles in different ways.

Moreover, the quantitative results in Table 4 showed some differences between the frequency and percentage of different functions of RMs in different RAs. As can be seen, the most frequent function of RMs is the explanation function which accounted for $54.3 \%$ of the RMs in computing engineering, $48.3 \%$ in applied linguistics, and $46.6 \%$ in physics articles. In contrast, the least frequent functions were math with $0 \%$ in applied linguistics articles and conclusion with $0.9 \%$ in computing engineering and $0.3 \%$ in physics.

According to the frequency of used functions of RMs, it can be concluded that most of the time writers use the functions that are related to the interpretation of explicit meaning including identification, specification, and explanation, and they use implicit meaning functions (conclusion and math) quite rarely. It seems that the writers in pure sciences use RMs more than the writers in other sciences such as applied sciences and humanities, and these markers help writers to expand, specify, clarify, or define what they have written, as illustrated in the above excerpts from the articles.

\subsection{DISCUSSION}

The first question asked if there are any cross-disciplinary differences in the types of RMs in research articles. Data analysis confirmed that there were statistically significant differences between applied linguistics, computer engineering, and physics in this regard. It seems that because these three disciplines belong to different fields of science, namely, humanities, applied sciences, and pure sciences respectively they differ from each other in using RMs in their research articles. This can highlight the significance of the acceptable conventions of applying reformulation markers by researchers and writers of articles while writing in their fields. 
In relation to the frequency of RMs, applied linguistics, computer engineering, and physics articles showed divergence. As was observed, authors in physics made a greater use of RMs. This can be also justified in light of the different conventions and expectations set by each discipline framework to develop coherent and meaningful stretches of writings (Creswell, 2009), research articles in this case. The higher use of RMs in physics texts might be due to the requirements of this discipline for further elucidation of the propositions which are embedded in physics articles so that they become cohesive, coherent, and hence more meaningful.

As Hyland (2008) believes, different disciplines show distinct behaviors in developing texts and employing textual elements because of their distinct nature. The differences may be related to the distinct nature of different disciplines. It can be said that, due to these distinctive natures, RMs were used with different frequencies across the three disciplines. It means that the authors in different disciplines rely on different conventions to handle RMs. This suggests the language of the research articles in physics contains more RMs than the language of the other disciplines. Thus, it can be concluded that the distinct nature of physics might be a reason why authors utilize RMs more frequently than the authors of the two other disciplines. Another reason for the greater use of RMs by writers of physics RAs might refer to their aversion to be more explicit in their writing which runs counter to the higher frequency of reformulation markers as evidence of explicitation (Mutesayire, 2005), and it is due to the nature of physics that is a discipline that needs to be explicit and needs a lot of explanation and specification. On the other hand, the role of RMs is to explain, specify, and elaborate the information, so the writers of physics RAs have to use RMs frequently.

Concerning the types of RMs in applied linguistics, physics, and computer engineering RAs, there was somehow no dissimilarity. Among the types in focus, i.e. was the most frequent one in these disciplines, whereas that is to say and in other words were the least frequent RMs. In other words, writers of articles tend to employ this shortened reformulation marker more frequently to explain what has already been mentioned. This higher frequency is probably due to its simpler and shorter form compared to that is to say and in other words which encourages authors to use it significantly more often.

Regarding the second question in physics discipline, explicit meaning functions, identification, specification, and explanation included the majority of RMs used in this discipline. As stated by Murillo (2012), explicit meaning functions assist in reference assignment and introducing the referents. This means that physics texts tend to use more functions of this type to introduce and clarify referents compared to the other disciplines. This might also be related to the distinctive nature of this discipline as it is more abstract than the other disciplines. Therefore, the current study substantiates this intangible nature of physics which can result in a higher percentage of explicit meaning functions. An even more important issue with a linguistic approach to disciplinary discourse has been pointed out by Airey and Lunger (2006). They argue that the disciplinary discourse of physics includes not merely the spoken and written linguistic modes, but also the mathematical, the visual (graphs, etc.), the active (carrying out experiments), and the instrumental (the type of information that each instrument gives). Knowing physics, they argue, is knowing all these modes and integrating them. One can well imagine that ideographic philosophy, for example, is mainly constructed by written words, but the same is not true for all disciplines, where key aspects of the discourse may be constructed by other modes. 
In relation to the computer engineering RAs, explicit meaning functions, identification, specification, and explanation occurred more than the other functions. Therefore, it can be said that since the language of this discipline is replete with $\mathrm{RMs}$ of these functions, the authors tend to use these functions more densely. These markers reflect the image of the reader that the writer has, regarding previous knowledge and processing recourses, and thus contribute significantly to the analysis of the writer-reader interaction in the text (Murillo, 2012).

Studies within the area of Discourse Analysis and Contrastive Rhetoric demonstrate that writers are sensitive to the different expectations of their readers and that these expectations may differ across disciplines, languages, and cultures (Connor, Nagelhout \& Rozycki, 2008; Hoey, 2001; Moder, Lynn \& Martinovic-Zic, 2004). In some languages, the burden is on readers for extracting the meaning from the text, while in more 'reader-friendly' languages, writers have to facilitate understanding and to show consideration for the reader (Hinds, 1983, 1984). Research has described English language as a writer responsible language in many genres and in comparison with other languages (Connor, 1996). Whereas the writers know themselves as responsible to facilitate understanding, they use RMs as a device to achieve their goal.

With regard to the RAs of applied linguistics, explicit meaning functions were the most frequent ones. These functions help the reader to interpret and specify the explicit content and clarify the explicit meaning to a certain extent; they are used to narrow down the possible implications to be extracted (Murillo, 2012). Based on the research on vocabulary, we can conclude that the used words are very different across disciplines and even that the same words will be used with different frequencies and often with different meanings in different fields. This means that we need to understand the distinctive ways they have of asking questions, criticizing ideas, and presenting arguments, so we can help students participate effectively in their learning.

Regarding conceptual meaning functions (definition and denomination), writers of the three disciplines applied them in a similar way. These functions are used to provide a definition for terms that belong to specialized fields and to provide specific terminology respectively. All the three disciplines resorted to these functions to generate necessary background knowledge for interpretation by introducing definitions and terminology of specialized terms because terms can have different meanings in different disciplines. Moreover, since English is a writer-responsible language, the writers, as their duty, try to provide the related definitions and terminology to do their duty and convey meaning clearly. Some functions of this kind are exemplified below:

\section{Definition Function}

1. "Adsorption can be divided into two general classes on the basis of the strength of interaction between the adsorbing molecule ("adsorptive") and the solid surface ("adsorbent"): physisorption (i.e., physical adsorption) and chemisorptions (i.e., chemical adsorption)." (Atomic Energy Journal, 2013, Conclusion) 


\section{Denomination Function}

2. "Note that CIM Bull (that is, the Canadian Bulletin of Mining and Metallurgy) is in the sixth position on the list generated by our indicator." (Journal of Computer-Mediated Communication, 2012, Introduction)

In case of implicit meaning functions including mathematical operation and conclusion, conclusion function introduces a conclusion from the previous information and mathematical operations introduce the result of mathematical operations from previous data. They were the least frequent functions in these three corpora. These functions are not frequent in applied linguistics RAs due to the nature of applied linguistics RAs as qualitative RAs. These types of RAs try to explain, specify, and elaborate the issues using explicit meaning functions and conceptual meaning functions. Physics and computer engineering are quantitative RAs, but they also try to describe the results and conclusion using other functions than implicit knowledge functions because problems in these disciplines need a lot of explanations to show the issues more clearly, whereas because English writers are responsible to help readers understanding, they should use explanation, specification and identification more than other functions as they cannot convey their meanings just by using implicit meaning functions. The followings are some of these functions in the corpora:

\section{Conclusion Function}

3. "People are also more or less sympathetic to farmers' concerns. That is, why India is trying to evolve its own system for protecting plant breeders rights." (English for Specific Purposes, 2010, Introduction)

4.

\section{Mathematical Operation Function}

5. "Using the values of CaSi202N2:Eu2+, i.e., $\mathrm{N}=12, \mathrm{xc}=0.02$, and V = 1587 Ã...3; Eq. (2) Yields Rc = 23.3 Ã." (Atomic Energy Journal, 2008, Result)

In answering the first question, concerning the frequency, type and functional differences of RMs across the different disciplines, it should be mentioned that the three disciplines were different in using certain functions of RMs, and there were significant differences in the type of RM used through the three disciplines. In a study on disciplinary variation in the use of lexical bundles, Author, Jalilifar, and Zarea (2013) analyzed the use of lexical bundles in different disciplines, and the results revealed that lexical bundles are used differently across disciplines due to certain factors. As Hyland (2008) believes, different disciplines have different ways to develop texts and use textual elements because of their distinct nature. The differences, then, may be related to the distinct nature of different disciplines. Therefore, the various frequencies of different functions in the three disciplines may be due to the distinctive natures of different disciplines. It means that the writers of different disciplines use different conventions to utilize RMs.

In a nutshell, the findings of our research contribute to the discussion that writers in different disciplines draw on different resources to develop their arguments, establish their credibility, and 
persuade their readers' means. Such considerations underlie the conventions which guide scholarly writing for academic publication. Thus, writers need to take into account the ways texts are created in these disciplines.

\subsection{CONCLUSION}

This study compared the use of reformulation markers in research articles of three disciplines, namely, applied linguistics, computer engineering, and physics. The results of the study indicated that there are disciplinary variations in the use of RMs. In other words, different disciplines differ in terms of their types and functions. Another conclusion to draw is that writers of physics RAs tend to use RMs much more frequently than writers of applied linguistics and computer engineering RAs. This can be related to the fact that these disciplines belong to different categories. Furthermore, it was found that functions related to the interpretation of explicit meaning are the most frequent functions; in contrast, implicit meaning functions are the least frequent ones in these disciplines.

Results of the current study can have implications for writers of different disciplines to be aware of different conventions governing each particular discipline. In addition, they help non-native writers; if these writers, who write in English as a foreign language, become aware of the differences and similarities of the use of reformulation markers in the target language, they will be able to apply them more effectively and appropriately.

Having a better understanding of RMs and their similarities and differences, English for Academic/Specific Purposes (EA/SP) students and researchers can develop a good command of RMs in English and write texts. As Martin (2003) suggests, contrastive studies of this type can be especially helpful to novice academics who wish to publish their works in international and national journals and, therefore, need to know the conventions which are favored by the English-speaking discourse community. To achieve their goals, they are required to be aware of disciplinary and cultural conventions of their discourse community. If researchers have a good understanding of RMs, they can communicate more efficiently in the target language and be more successful members of their discourse community.

Notwithstanding the merits of a corpus-based approach to the teaching of reformulation markers for ES/AP classes, the authors believe that this should be tied to a genre-based approach. We assume that RMs are always selected in relation to their communicative function in the immediate context in which they occur and that each new writer has to make an appropriate choice in context, which may or may not reflect what has previously been commonly used according to a corpus analysis. Therefore, it would not help an advanced student, for instance, to be self-directed if we asked them to determine a choice based on a corpus study alone. To use a simple metaphor, it can be said that a corpus is perhaps a poor master but a good servant.

One of the limitations of this study was the low number of studies, disciplinary ones in particular, which directly consider reformulation markers. This made our work difficult to compare the findings of the current study with them to gain more insight and depict a better picture of reformulation and its use across different disciplines. Another limitation that we faced is related to the 
fact that there were not any studies on the application of RMs in Persian in the Iranian context. The majority of the previous studies compared RMs in English, Spanish, and, Catalan.

\section{REFERENCES}

Airey, J. \& Cedric, L. 2006, June. Languages, Modality and Disciplinary Knowledge. $2^{\text {nd }}$ Conference on Integrating Content and Language in Higher Education, Maastricht.

Author, M., Jalilifar, A. \& Zarea, M. 2013. A Corpus Study of Lexical Bundles Across Different Disciplines. The Iranian EFL Journal. 9(6): 11-35.

Author, \& Matouri, H. 2017. Comparative Study of Reflexive Metadiscourse in Applied Linguistics Research Articles. International Journals and in Iranian National Journals. ARTESOLESP E-Journal. 7(1): 15-28.

Author, \& Nooreddinmoosa, M. 2018. Informality in Applied Linguistics Research Articles: Comparing Native and Non-Native Writings. Eurasian Journal of Applied Linguistics. 4(2): 349-373.

Alise, M. 2007. Disciplinary Differences in Preferred Research Methods: A Comparison of Groups in the Biglan Classification Scheme. An Unpublished Doctoral Dissertation. Louisiana State University And Agricultural And Mechanical College, Baton Rouge, LA.

Bach, C. 1996. Reformular: una operacion argumentativa aseptica? Estudio del conector de reformulacion parafrastica es a dir. Sendebar. 7: 255-271.

Bach, C. \& Cuenca, M. J. 2007. Contrasting the Form and Use of Reformulation Markers. Discourse Studies. 9(2): 149-175.

Baker, M. 2004. A Corpus-based View of Similarity and Difference in Translation. International Journal of Corpus Linguistics. 9(2): 167-193.

Beauvais, P. J. 1989. A Speech Act Theory of Metadiscourse. Written Communication. 6: 11-30.

Blakemore, D. 1987. Semantic Constraints on Relevance. Oxford: Blackwell.

Blakemore, D. 1993. The Relevance of Reformulations. Language and Literature. 2: 101-120.

Braxton, J. M., \& Hargens, L. L. 1996. Variation Among Academic Disciplines: Analytical Frameworks and Research. In J.C. Smart (Ed.). The Handbook of Theory and Research in Higher Education. New York, NY: Agathon Press. 1-46.

Carter, R. 2003. Language Awareness. ELT Journal. 57: 64-65.

Cabre, M. T. 1995. Les relacions parafrastiques. In: Artigas, Rosa (Ed.). El significat textual. Generalitat de Catalunya Barcelona. 73-81.

Connor, U., Nagelhout, E. \& Rozycki, W. 2008. Contrastive Rhetoric: Reaching to Intercultural Rhetoric. Amsterdam: John Benjamins.

Connor, U. 1996. Contrastive Rhetoric: Cross-cultural Aspects of Second Language Writing. New York: Cambridge University Press.

Creswell, J. W. 2009. Research Design: Qualitative, Quantitative, and Mixed Methods Approach. 3rd ed. Los Angeles: SAGE.

Crismore, A. \& Farnsworth, R. 1990. Metadiscourse in Popular and Professional Science Discourse. In W. Nash (Ed.). The Writing Scholar Newbury Park: Sage Publications. 119-136. 
Cuenca, M. J. 2003. Two Ways to Reformulate: A Contrastive Analysis of Reformulation Markers. Journal of Pragmatics. 35(7): 1069-1093.

Fuentes, R. C. 1993. Conclusivos y reformulativos. Verba. 20: 171-198.

Gulich, E. \& Kotschi, T. 1983. Les marqueurs de reformulation paraphrastique. Cahiers de linguistique française. 5:305-351.

Gulich, E. \& Kotschi, T. 1995. Discourse Production in Oral Communication. In U.M. Quasthoff (Ed.). Aspects of Oral Communication Berlin/ New York: Walter de Gruyter. 30-66.

Hagstrom, W. 1964. Anomy in Scientific Communities. Social Problems. 12(2): 186-195.

Halliday, M. A. K. 1978. Language as Social Semiotic: The Social Interpretation of Language and Meaning. London: Edward Arnold.

Hargens, L. L. 1975. Patterns of Scientific Research: A Comparative Analysis of Research in Three Scientific Fields. Washington, DC: American Sociological Association.

Hinds, J. 1983. Contrastive Rhetoric: Japanese and English. Text. 3(2): 183-196.

Hinds, J. 1984. Retention of Information Using a Japanese Style of Presentation. Studies in Linguistics. 8(1): 45-69.

Hoey, M. 2001. Textual Interaction. London: Routledge.

Hyland, K. 1998. Persuasion and Context: The Pragmatics of Academic Metadiscourse. Journal of Pragmatics. 30: 437-455.

Hyland, K. 1999. Disciplinary discourses: Writer Stance in Research Articles. In C. N. Candlin \& K. Hyland (Eds.). Writing: Texts, Processes and Practices. London: Longman. 99-121.

Hyland, K. 2000. Disciplinary Discourses: Social Interactions in Academic Writing. London: Longman. Hyland, K. 2004. Disciplinary Discourses: Social Interactions inAcademic Writing. University of Michigan Press.

Hyland, K. 2005. Metadiscourse. London: Continuum.

Hyland, K. 2008. As can be seen: Lexical bundles and disciplinary variation. English for Specific Purposes. 27(1): 4-21.

Hyland, K. \& Tse, P. 2004. Metadiscourse in Academic Writing: A Reappraisal. Applied Linguistics. 25(2): 156-177.

Jalilifar, A. R. \& Author, M. 2007. How Explicit Instruction Makes a Difference: Metadiscourse Markers and EFLlLearners' Reading Comprehension Skill. Journal of College Reading and Learning. 38(1): 35-52.

Jalififar, A. R., Z. G. Shooshtari. 2011. Metadiscourse Awareness and ESAP Comprehension. Journal of College Reading and Learning. 41(2): 53-74.

Kahkesh, M., \& Author. 2017. A Comparative Study of Metadiscourse Markers in English and Persian University Lectures. Research in Applied Linguistics. 8: 125-135.

Kuhn, T. S. 1970. The Structure of Scientific Revolutions. $2^{\text {nd }}$ ed. Chicago, IL: University of Chicago Press.

Lodahl, J., \& Gordon, G. 1972. The Structure of Scientific Fields and the Functioning of University Graduate Departments. American Sociological Review. 37(2): 57-72.

Martin, M. P. 2003. A Genre Analysis of English and Spanish Research Paper Abstracts in Experimental Social Sciences. English for Specific Purposes. 22: 25-42. 
Moder, C. \& Martinovic-Zic, A. 2004. Discourse Across Languages and Cultures. Amsterdam: John Benjamins.

Murillo, S. 2004. A Relevance Reassessment of Reformulation Markers. Journal of Pragmatics. 36(11): 20590-2068.

Murillo, S. 2007. A Contribution to the Pragmalinguistic Contrastive Study of Explicatory Reformulative Discourse Markers in Contemporary Journalistic Written English and Spanish.Unpublished Doctoral Dissertation. Universidad de Zaragoza.

Murillo, S. 2012. The Use of Reformulation Markers in Business Management Research Articles. International Journal of Corpus Linguistics. 17(1): 64-90.

Mutesayire, M. 2005. Cohesive Devices and Explicitation in Translated English - A Corpus-based Study. Unpublished PhD thesis, University of Manchester.

Quirk, R., Greenbaum, S., Leech, G. \& Svartvik, J. 1985. A Comprehensive Grammar of the English Language. Harlow: Longman.

Schourup, L. 1999. Discourse Markers. Lingua. 107: 227-265.

Swales, J. 1993. Genre Analysis: English in Academic and Research Settings. Cambridge: Cambridge University Press.

Swales, J. 2004. Research Genres: Exploration and Applications. Cambridge: Cambridge University Press.

Thoiron, P. and Bejoint, H. 1991. La place de la réformulation dans les textes scientifiques. Meta. 36(1): 101-10.

Vande Kopple, W. J. 1985. Some exploratory discourse on metadiscourse. College Composition and Communication. 36(1): 82-93.

Wells, G. 1992. The Centrality of Talk in Education. In K. Norman (Ed.). Thinking Voices: The Work of the National Oracy Project London: Hodder an Stoughton. 282-301.

Wilson, D. \& Sperber, D. 2004. Relevance Theory. In L. R. Horn \& G. Ward (Eds.). The Handbook of Pragmatics Oxford: Blackwell. 607-632.

Xiao, R. 2011. Word Clusters and Reformulation Markers in Chinese and English. Languages in Contrast. 11(2): 145-171. 